\title{
La noción de "creencia" y su manifestación en el uso o vigencia. Hacia una fenomenología del mundo social en José Ortega y Gasset ${ }^{\star}$
}

\author{
Daniel Esteban Quiroz Ospina \\ Universidad de Antioquia, Medellín, Colombia \\ danielfilos.92@gmail.com \\ https://orcid.org/0000-0002-2952-4743
}

\section{RESUMEN}

En este artículo se busca dar cuenta de una reflexión fundamental en la filosofía de José Ortega y Gasset. A partir de una crítica al punto de vista moderno, representado en este caso por Husserl, Ortega postula su idea de la vida humana como realidad radical. El análisis de la "presencia" de la vida conlleva al problema de la correlación ser humano-mundo en tanto pregunta por cómo se desenvuelve el yo en la circunstancia. Ortega responde a esta cuestión desde la noción de "creencia", la cual es analizada aquí como punto central para pasar al tema fundamental: la fenomenología del mundo social, la cual está enmarcada en los conceptos de "uso" y "vigencia". Así, este trabajo quiere dar cuenta de un camino fenomenológico que va de lo abstracto a lo concreto, desde la "presencia" de la vida hasta la existencia de la sociedad en tanto circunstancia fundamental de toda vida humana.

Palabras clave: vida humana; circunstancia; creencia; uso; vigencia.

* Cómo citar: Quiroz Ospina. D. (2019). La noción de "creencia" y su manifestación en el uso o vigencia. Hacia una fenomenología del mundo social en José Ortega y Gasset. Ciencias Sociales y Educación, 8(15), 65-86. DOI: https://doi.org/10.22395/csye.v8n15a4

Recibido: 2 de diciembre de 2018.

Aprobado: 4 de abril de 2019. 


\section{The Notion of 'Belief' and its Manifestation in Use or Validity. Towards a Phenomenology of the Social World in José Ortega Y Gasset}

\section{ABSTRACT}

This article aims to give an account of a fundamental reflection on the Ortega y Gasset's philosophy. Parting from critics from the modern point of view and represented, in this case by Husserl, Ortega states his idea of human life as a radical reality.

The analysis of the "presence" of life entails the problem of the correlation human being-world as it questions how the self develops in the circumstance. Ortega's answers to this question from the notion of "belief", which is analyzed here as a central point for getting to the fundamental theme: the phenomenology of the social world, which is framed in concepts such as "use" and "validity". Thus, this work wants to give an account of a phenomenological path parting from the concrete, from the "presence" of life and up to the existence of society as a fundamental circumstance of all human life.

Keywords: human life; circumstance; belief; use, validity.

\section{A noção de "crençca" e sua manifestação no uso ou vigência. Rumo a uma fenomenologia do mundo social em José Ortega y Gasset}

\section{RESUMO}

Este artigo trata de apresentar uma reflexão fundamental na filosofia de José Ortega y Gasset. A partir de uma crítica do ponto de vista moderno, representado, neste caso, por Husserl, Ortega defende sua ideia da vida humana como realidade radical. A análise da "presença" da vida implica o problema da correlação ser humano-mundo ao mesmo tempo que pergunta por como o eu é desenvolvido na circunstância. Ortega responde a essa questão com base na noção de "crença", a qual é analisada aqui como ponto central para passar ao tema fundamental: a fenomenologia do mundo social, que está delimitada nos conceitos de "uso" e "vigência". Assim, este trabalho pretende apresentar um caminho fenomenológico que vai do abstrato ao concreto, desde a presença da vida até a existência da sociedade como circunstância fundamental de toda vida humana.

Palavras-chave: vida humana; circunstância; crença; uso, vigência. 


\section{Introducción}

Casi todos los lectores de José Ortega y Gasset coinciden en que su sentencia "yo soy yo y mi circunstancia, y si no la salvo a ella no me salvo yo" (Ortega, 1966, I, p. 322) es la gran síntesis de su labor filosófica. Sin embargo, hay mucho más por escudriñar, no sólo en esta frase, sino en todos sus escritos. En efecto, el autor de Meditaciones del Quijote tuvo una preocupación fundamental por la vida humana, por el mundo común de la cotidianidad en que esta se desenvuelve siempre; solo así podía entender lo que pasaba en él y, más exactamente, su doliente derredor, su invertebrada España.

El mundo de la cotidianidad en que se desenvuelve la vida humana está lleno de personas y de cosas. Esto es una obviedad, pero detrás de las obviedades está lo fundamental. Las personas y las cosas nos aparecen de cierta forma, es decir, lo que se puede entender por "nuestro mundo" también está compuesto por maneras de ver, razones, sentimientos y emociones que se entremezclan y aparecen en situaciones concretas. También hay formas de decir, opiniones, acuerdos y desacuerdos que son el motor de este mundo y que Husserl llamó acertadamente "mundo de la vida".

El mundo de la vida siempre está presente, pues en este se inserta todo cuanto puede hacer un ser humano. Esta presencia del mundo no es otra cosa que la presencia de la vida misma; esa es la aseveración básica de Ortega a partir de su crítica al punto de vista de la Modernidad, pues el estar presente de la vida no es necesariamente ser pensado explícitamente por una conciencia, sino mostrarse siempre en cada acción y en cada situación. Eso que se muestra, la "presencia" de la vida, no es nada etéreo, sino que, como se verá a lo largo de este trabajo, está lleno de contenido. Se verá más claro en el primer capítulo, cuando se vea la crítica orteguiana al punto de vista moderno representado en su etapa más tardía por la fenomenología de Edmund Husserl. De dicha crítica saldrá el punto de partida fundamental: la realidad radical o primaria, en la cual se insertan todas las demás realidades, es la vida humana. No lo es el mundo exterior, ni el pensamiento, ni la conciencia.

Ahora bien, el punto central de esta cuestión del mundo que rodea a la vida humana es que sus aristas suelen manifestarse sin que el individuo lo haya sacado de su esfuerzo intelectual o, más aún, sin que se lo proponga explícitamente. La gran mayoría de las opiniones y formas de ver el mundo no fueron inventadas por el individuo que las emite, sino que fueron heredadas por otros: la familia, la sociedad o la época. Esta es la cuestión fundamental que el pensador español condensa en el concepto de "creencia". Para poder desenvolverse en el mundo, el ser humano debe entenderlo en sus líneas generales. Entender, como se verá, es para Ortega tener una convicción sobre algo en la medida en que, con ello, 
se puede saber a qué atenerse frente a lo que rodea. Pero estas convicciones raras veces son hechas por los individuos, sino que son inoculadas. Los seres humanos viven en creencias, y es con base en ellas que la sociedad tiene su funcionamiento. Esto es lo que se verá a lo largo del tercer y del cuarto capítulo.

Con base en este punto central, la creencia, se llegará a la cuestión central de este trabajo. La fenomenología orteguiana muestra cómo la vida humana se desenvuelve en un mundo lleno de supuestos implícitos más allá del ámbito de la conciencia. Estos supuestos se manifiestan, en términos concretos, en el funcionamiento fundamental de la sociedad: la cuestión de los usos. Los usos son, como se verá con más profundidad, todos los comportamientos o formas de pensar que una sociedad impone a sus individuos bajo una coacción implícita o explícita. Se verá cómo este fenómeno es un componente fundamental de toda vida humana en la medida en que tales usos de la sociedad son parte de lo que Ortega llama la "circunstancia", es decir, todo aquello con lo que un ser humano "debe contar" a lo largo de su vida.

Todo el recorrido de este trabajo es un camino desde una reflexión fenomenológica abstracta hasta su manifestación más concreta: desde la crítica de la fenomenología de la conciencia hasta la fundamentación de una fenomenología del mundo social. Es así como se puede resumir buena parte del trabajo filosófico de José Ortega y Gasset en textos fundamentales como ¿Qué es filosofía?, Principios de metafísica según la razón vital, Ideas y Creencias, El hombre y la gente, entre otros.

\section{La crítica al punto de vista moderno. Ortega crítico de Husserl}

Este artículo pretende exponer las consideraciones del filósofo español José Ortega y Gasset acerca de la sociedad en tanto fenómeno. Estas reflexiones filosóficas parten de una serie de presupuestos metafísicos, los cuales, a su vez, tienen su base en una crítica fundamental a la fenomenología de Husserl. Dicha crítica está basada en el prejuicio propio de su época, a saber, que la fenomenología husserliana es esencialmente idealista. Este prejuicio tuvo su razón de ser en el escaso conocimiento que se tenía de su filosofía porque había pocas obras publicadas en la primera mitad del siglo XX. De esta manera, Ortega y Gasset no escapó de tal prejuicio a la hora de considerar críticamente la fenomenología husserliana.

El contenido fundamental de estas consideraciones críticas sobre Husserl aparece en dos ensayos: Prólogo para alemanes (1934) y Apuntes sobre el pensamiento (1941). Ortega muestra en estos trabajos que la fenomenología es la forma más depurada y acabada del idealismo, cuyo análisis de la conciencia ha alcanzado el nivel de detalle suficiente para que las fallas de tal análisis sean 
eventualmente evidentes. El español entiende por "idealismo" todo planteamiento filosófico en el cual se da por supuesto que la realidad primera o "radical" es la conciencia. En la medida en que la fenomenología husserliana postula que toda realidad es esencialmente "para" la conciencia, puede ser considerada como una filosofía idealista ${ }^{1}$.

En el Prólogo para alemanes, Ortega critica el concepto husserliano de "conciencia pura" para demostrar que esta no solo no es la realidad primaria, sino que la conciencia solo puede ser ingenua o ejecutiva ${ }^{2}$. El español entiende que la realidad primaria para Husserl es la conciencia pura que da cuenta de las vivencias, es decir, que se limita a corroborar la vivencia en vez de experimentarla como tal. La conciencia, como dice Ortega (1965), no siente, sino que se limita a ver su sentir; no piensa, sino que se limita a corroborar el pensar. En suma, "ese yo es, pues, puro ojo, puro e impasible espejo, contemplación y nada más." (VIII, p. 48). Por consiguiente, la realidad externa solo sería en tanto captable por la conciencia que corrobora vivencias.

Las condiciones principales para que una realidad sea considerada radical o primaria son, según Ortega (1964), que sea evidente por sí misma y que no sea producto de una manipulación del intelecto humano (Cf. VII, p. 335ss.). El problema de la conciencia pura como realidad radical es que no cumple este requisito. Esta realidad no se impone a sí misma, sino que es producto de un procedimiento llamado epojé o reducción. Husserl entiende la "reducción" como el medio por el cual se pone entre paréntesis la creencia en la realidad de lo que aparece para limitar la cuestión a las formas en que puede darse una vivencia: percepción, imaginación, recuerdo, etc. Esto se hace con el objetivo de descubrir las esencias de los fenómenos y, eventualmente, captar la esencia de la conciencia pura como polo de toda vivencia posible ${ }^{3}$.

1 La crítica a Husserl no es el único intento de Ortega por superar el idealismo. Tal superación es, de hecho, un motivo fundamental de su filosofía, pues de esta tarea depende la justificación de su presupuesto metafísico, el cual consiste en que la realidad primera es la vida humana o, lo que es lo mismo, la correlación entre el yo y la circunstancia. Así las cosas, el filósofo español se dedicó a esta cuestión en múltiples obras como Qué es filosofía, Principios de metafísica según la razón vital, La razón histórica, etc.

2 Este concepto de "ejecutividad", esencial en la reflexión fenomenológica orteguiana, se refiere al carácter "presencial" pero no "objetivo" o "consciente" de la relación entre el yo y el mundo. Cuando se realiza un acto o se tiene una vivencia, la presencia de esta consiste meramente en su cumplimiento, no en la verificación por parte de un yo que sirve de polo a las vivencias, tal como lo piensa Husserl; lo mismo sucede con la presencia del propio yo y, finalmente, con el mundo. El mundo se presenta, en consecuencia, en la ejecución misma del vivir, no en una conciencia explícita. Ortega (2010) lo explica de la siguiente manera: "Yo me soy presente sin que necesite percibirme: al contrario, al percibirme, mi yo ejecutivo e íntimo, mi intraser, no aparece más ni menos que cuando no ejercito una 'percepción interna' o 'inmanente'. Y como el 'yo', todos mis 'actos'. Y como mis 'actos', el 'mundo' todo hacia quien suelen dirigirse. (Estos 'actos' así presentes no son lo que la objetivación psicológica llama 'actos', ni mi 'yo' es el psicológico, sino mi yo y mis actos vivientes)” (VIII, p. 202).

3 Esta explicación del proceso de la epojé está basada en el texto husserliano que, a mi modo de ver, define con más claridad sus aspectos fundamentales: el artículo "Fenomenología" de la Encyclopaedia Britannica (Cf. Husserl, 1990). 
La epojé supone entonces un cambio de visión que consiste en pasar de la vivencia misma a su contemplación. Esta es la manipulación que, según Ortega, hay que hacer para descubrir la conciencia pura. En este orden de ideas, como la conciencia pura no es algo dado inmediatamente, sino el producto derivado de una acción humana, no puede ser la realidad radical.

Ahora bien, para Ortega, la conciencia pura no solo es ilegítima como realidad radical en tanto es producto de una manipulación, sino que la reflexión misma de la cual resulta no tiene sentido. En efecto, el ser humano vive la realidad constantemente y la da por hecho o, como lo expresa el español, está en permanente "ejecución" con la realidad. Husserl no ignora este hecho; dicha ejecución es lo que éste llama "actitud natural". No obstante, el alemán pretende que uno puede volver sobre una vivencia que ha tenido y hacer la respectiva reflexión. ¿Sobre qué se reflexiona? Sobre una vivencia que se ha tenido. Por ende, para Ortega (1964), solo se puede reflexionar sobre algo que ya ha pasado, es decir, un recuerdo. Sin embargo, según Ortega, la situación de una conciencia ingenua o en actitud natural no cambia, puesto que, si bien el hombre hace una reflexión, está igualmente viviendo una realidad inmediata, a saber, el recuerdo. La realidad de reflexionar sobre un recuerdo sigue siendo tan ingenua como la vivencia recordada. Es por esto que concluye Ortega (1965): "Yo sigo siendo ahora un hombre real que encuentra ante sí, por tanto, en el mundo, la realidad 'conciencia'" (VIII, p. 49). Por otro lado, Ortega afirma que no se puede suspender la realidad de la vivencia recordada en la reflexión. Se puede observar o analizar el recuerdo, pero en tanto la realidad de la vivencia ya pasó, no puede ser "desrealizada" desde su recuerdo en una suspensión, como lo pretende Husserl con la "reducción". En este sentido, el ser humano tiene que enfrentarse necesariamente con algo fuera de él, es decir, con algo del mundo. Para Ortega, es imposible una conciencia "desmundanizada".

La conclusión fundamental de este análisis de Ortega (1965) es que la irreflexividad de las vivencias no puede ser revocada por una conciencia que corrobora el estatuto de la vivencia. Mientras se vive, el ser humano está abocado a vivir, no a volver sobre sí. Por otro lado, la reflexión sigue siendo una vivencia como cualquier otra. En suma, la conciencia pura no puede ser la realidad radical porque: 1) no es una realidad que se impone a sí misma, sino que es producto de una construcción mental del pensador; 2) y porque, aun como realidad construida, es un equívoco en la medida que no hay manera de cancelar la ejecutividad de las vivencias (VIII, p. 50).

A partir de su consideración sobre los problemas de la fenomenología husserliana, Ortega (1965) propone su idea de la realidad radical: la coexistencia del ser humano (уо) con una realidad irrevocable en la cual vive (mundo o circunstancia). "Lo que verdaderamente hay y es dado es la coexistencia mía 
con las cosas, ese absoluto acontecimiento: un yo en sus circunstancias" (VIII, p. 51). La realidad primaria que realmente se impone a sí misma es la vida de cada cual. Además, esta no es un hecho bruto sino un acontecimiento, es decir, la coexistencia entre el yo y la circunstancia es tal que en ella algo le pasa al ser humano. Lo que hay inmediatamente es un acontecimiento que consiste en vivir en una circunstancia. De ahí que para Ortega (1965) la vida no es una cosa, sino un drama (Cf. VIII, p. 52). Este carácter de la vida humana, según el cual no es algo que está ahí como un objeto cualquiera, sino que es un acontecimiento en el que el ser humano está indefectiblemente involucrado, es fundamental para entender otro de los presupuestos metafísicos de la filosofía orteguiana, a saber, el quehacer del yo con la circunstancia.

\section{Circunstancia e interpretación}

La crítica a la fenomenología husserliana es apenas uno de los recursos de Ortega para dar la vuelta, no solo al idealismo, sino también al prejuicio que ha permanecido en toda la historia de la filosofía. La filosofía no solo ha sido idealista - ha supuesto el pensamiento como la realidad primera-, sino que antes fue realista, es decir, dio por sentado que la realidad primera era el mundo externo. No obstante, ambos supuestos tienen un prejuicio común: la realidad primera es un ser estático o fijo; la filosofía ha supuesto que lo real es lo idéntico, lo que se basta a sí mismo. Para Ortega (1964), la filosofía ha sido eminentemente "intelectualista" (Cf. VI, p. 30ss.).

Ahora bien, la idea de un ser idéntico es para Ortega una construcción intelectual y no algo que se manifieste inmediatamente. El postulado de la vida humana como realidad radical parte entonces de una superación del supuesto intelectualista. Para Ortega, la realidad no puede ser reducida al concepto idéntico y suficiente porque éste es producto del intelecto y, en el fondo, éste no es más que una función movida por el contexto de una vida humana. La vida humana es algo anterior al intelecto y, por tanto, no es algo fijo o suficiente. Es en ese sentido que Ortega (1964) apela a no pensar la vida humana desde la idea de "naturaleza" porque la vida, como repite en Historia como sistema, no es una cosa, sino un drama (Cf. VI, p. 32).

Si la vida no es una realidad fija, entonces es una realidad incompleta o, como dice Ortega, "menesterosa". Por otro lado, si la vida es la coexistencia entre el yo y la circunstancia, entonces esta última tiene este carácter incompleto. Esto quiere decir que la coexistencia no es el estar una cosa independiente - yojunto a otra cosa independiente - mundo. Una de las formas como Ortega (1964) entiende el mundo es, por ejemplo, la siguiente: "el mundo es lo que está siendo para mí, en dinámico ser frente y contra mí, y yo soy el que actúo sobre él, el que 
lo mira, y lo sueña y lo sufre y lo ama o lo detesta" (VII, p. 410). La correlación entre el ser humano y el mundo no es una yuxtaposición de realidades cerradas en sí mismas. El mundo se presenta inmediatamente al ser humano como algo que lo afecta de una manera particular, pues en la vida se ama, se odia, se siente tristeza, se planea, se fracasa, etc. Incluso la más simple percepción de algo, como anota Rodríguez (1981), se encuentra involucrada en una serie de actos que se configuran en la forma de una vida individual particular afectada por lo que le rodea. Como cada vida es distinta, entonces el mundo se muestra dinámicamente y de forma tal que afecta al ser humano de alguna manera -cualquier intento de pensar el mundo desde un punto de vista universalista y neutral es ya un ejercicio interpretativo del intelecto humano, cuyo componente vital es irrenunciable.

En consonancia con la aparición del mundo en tanto afecta al ser humano, Ortega afirma que el carácter primario de la vida humana es su constante presencia o proximidad. Esta presencia no tiene que ver con la reflexión de las vivencias por parte de una conciencia, sino con el hecho de que todo cuanto aparece afecta la vida humana de alguna manera. Esta afectación, dice Ortega, hace que la vida consista en el hecho fundamental de "contar con" una circunstancia, con algo que aparece "para mí" porque me afecta de alguna manera, es decir, afecta de manera particular a cada cual. Ortega (2010) lo explica de la siguiente manera:

El 'para mí' vital es esa extraña presencia que mi vida tiene ante sí misma. Mi vida se compone solo de lo que me es en ese momento presente. La conciencia, la percepción, el pensamiento son patencias especiales de esa presencia universal y constitutiva de cuanto verdaderamente es mi vida. Es una presencia entitativa y no de objeto ante sujeto. Esta es solo una especie de aquella, a saber, la presencia consciente o cogitatio. Con el fin de expresar esa extraña presencia no intelectual, no noética y objetiva que ante mí tiene mi vida y en la nomenclatura reducir al mínimum la perturbadora interpretación idealista, diremos que 'el existir algo para mí' es un 'contar yo con' ello. Mi vida es contar yo conmigo y, a la vez, con algo que no soy yo y que llamaremos lo Otro=circunstancia o mundo. (VIII, p. 227)

Ahora bien, ¿qué quiere decir que todo aparece en la forma de un "contar con ello"? En primer lugar, al postular que la vida tiene una permanente "presencia", Ortega pone como elemento fundamental de la vida humana la inserción en una realidad imprescindible que escapa a la reflexión explícita de una conciencia. La vida se inserta primariamente en un ámbito prerreflexivo que se comprende de antemano - se cuenta con él一 en la medida en que la circunstancia afecta la vida de cada cual de maneras particulares.

Hasta ahora se ha hablado de la coexistencia del ser humano o de un "yo" con la circunstancia. Ciertamente este yo no es en absoluto un sujeto cognoscitivo 
o una conciencia, sino que es, según Ortega, un programa vital formado por las acciones que realiza en la circunstancia. Dicho programa que se configura con las acciones y decisiones de cada ser humano depende de cómo el mundo se le presente. La circunstancia moldea las acciones y decisiones de cada quien. De esta manera, aunque el mundo pueda ser visto como "igual" para todos de manera abstracta, éste se presenta inmediatamente de forma distinta según el programa vital de cada "yo". Ortega (2010) lo expresa de la siguiente manera en La razón histórica: "El perfil de cada yo oprime la circunstancia para subsistir en ella o realizarse y la circunstancia responde de diversa manera según cuáles sean las facciones, alibeos y gálibos del perfil o contorno de aspiraciones que es nuestro yo" (IV, p. 536).

Ahora bien, ¿cómo es posible que la circunstancia se presente de forma distinta a cada cual según su programa vital? En este punto, el carácter fundamental de la vida, el "contar con", adquiere mucho más contenido. Todo lo que aparece en la vida se presenta como algo que mueve a actuar y decidir. Como lo explica Rodríguez (1981) en su comentario: "Las cosas son, pues, primariamente instancias que me fuerzan a atenderlas, a contar — quiera o no- con ellas, a ocuparme y preocuparme de ellas y, en suma, a actuar en vista de ellas y de su instar" (p. 129). La circunstancia está compuesta de instancias que le imponen al ser humano la obligación de "hacer algo" con ellas. Estas pueden facilitar o dificultar la situación de tal manera que el ser humano actúa o decide de formas particulares. De aquí surgen dos consecuencias fundamentales para el hilo argumental de este trabajo: 1) el mundo se muestra de forma inmediata como un conjunto de "facilidades" y "dificultades" para el programa de vida que es cada quien. 2) La vida humana es un constante "quehacer" en una circunstancia con la cual cada ser humano configura su propia existencia.

Ya que la vida humana tiene el componente fundamental del quehacer de cada uno con su circunstancia, y ya que esta impone una serie de facilidades y dificultades para tal quehacer, el ser humano debe averiguar de algún modo en qué consiste la circunstancia en que se encuentra para poder asumirlo. Así pues, el ser humano debe indagar por lo que hay a su alrededor. Un determinado objeto puede facilitar o dificultar según la situación concreta. Una silla puede facilitar la labor de escribir un artículo si otorga una postura cómoda para el cuerpo o puede dificultar la labor de huir de un incendio si está atravesada en un corredor. Ejemplos aparte, se entiende la idea: lo que hay en el mundo aparece como facilidad o dificultad en el contexto de un quehacer. Ahora bien, ¿cómo saber en qué momento algo ayudará o estorbará? La vida sería imposible sin este conocimiento. De esta manera, el ser humano, como afirma Ortega en Qué es conocimiento, necesita anticiparse a las cosas, que estas no lo sorprendan en cada momento. Para poder anticiparse a las cosas, el ser humano necesita saber 
lo que estas serán siempre. Por ende, llega a plantearse la pregunta "¿qué es tal cosa?"; en suma, se pregunta por el "ser" de las cosas.

El ser de las cosas, dice Ortega, no es algo que esté en ellas de forma independiente al ser humano. Es, en cambio, un esquema que éste elabora a partir de lo que ha vivido con las cosas para poder saber qué hacer con ellas en el futuro, para poder saber a qué atenerse frente a ellas. Si el ser humano no sabe a qué atenerse frente a lo que le rodea, el quehacer de su vida sería imposible. Descubrir el ser de una cosa es en suma obtener una imagen con la que el ser humano pueda anticiparse a todos los contextos posibles en que algo pueda aparecer. Ortega (2010) lo explica de la siguiente manera en Qué es conocimiento:

El futuro de las cosas tiene que ser imaginado, construido, por el hombre. Y para ello tiene que pasar revista a cuanto de ellas recuerda, a lo que las cosas fueron hasta aquí, y procurar extraer de esa 'experiencia' una imagen o esquema de su conducta fija, de lo que son siempre, no en este o el otro instante. De esta suerte, construye el hombre tras cosas efectivas de cada instante la 'cosa permanente, inmutable'; en suma, el ser de las cosas. Cuando cree haberlo hallado sabe ya a qué atenerse respecto a ellas, dejan de ser inseguras, indecisas, fluidas. [...] Entonces puede el hombre decidir con alguna seguridad. Entonces sus decisiones tienen para él sentido y su vida es un caminar ordenado, en vez de un hundirse en el caos. (VIII, pp. 591-592)

Si el ser humano sabe lo que es su circunstancia con base en una elaboración esquemática, dicho saber bajo el cual se decide el quehacer es una interpretación. Las diversas interpretaciones sobre lo que son las cosas toman la forma de "convicciones". Al inicio de Historia como sistema, Ortega (1964) señala que decidir el quehacer de la vida sería imposible sin una serie de convicciones sobre la circunstancia (VI, p. 13). El ser humano solo puede vivir con base en convicciones, es decir, interpretaciones a partir de las cuales cada uno sabe qué hacer en una situación concreta.

La circunstancia es comprendida a través de estas interpretaciones que devienen convicciones. Esta se presenta inmediatamente como asuntos que afectan al ser humano en su quehacer, lo cual solo es posible porque ya se tiene una noción de aquello que aparece en la circunstancia, es decir, ya se tiene una convicción. Esto muestra en consecuencia que el hombre no llega al mundo sin convicciones para formárselas desde cero. Cuando el ser humano llega al mundo se encuentra con determinados otros que ya tienen un repertorio de convicciones sobre lo que es el mundo. Las convicciones de un hombre, dice Ortega, son en su gran mayoría heredadas por los demás hombres que ya se encontraban antes en un repertorio o conjunto interpretativo que Ortega (1964) llama "mundo" (Cf. V, p. 25ss.). Hasta ahora no se había distinguido entre "circunstancia" y "mundo", pero en En torno a Galileo, el español hace esta distinción: la circunstancia es 
el conjunto de facilidades y dificultades con que un ser humano se encuentra en el quehacer de su vida y el mundo es el conjunto de convicciones con que uno se encuentra para poder entender la circunstancia y anticiparse a ella en su quehacer. Esta diferencia sutil pero importante muestra que la circunstancia no es solo individual, sino que en la medida en que se comparten convicciones comunes, y estas son algo con lo que cada uno debe contar, también existe una circunstancia de una época o lugar. Las convicciones de una época y un lugar son una parte primordial de aquello con lo que cada cual debe enfrentarse en su vida; son una parte fundamental de su drama.

\section{Ideas y creencias}

En el anterior apartado se comentaba que la presencia de la vida humana consiste en contar con una circunstancia que obliga a actuar más allá de la reflexión explícita de una conciencia. ¿Con qué cuenta cada quién? Cuenta con su circunstancia, es decir, con facilidades y dificultades; en suma, con asuntos en que la vida se desenvuelve. El ser humano cuenta también con la obligación de hacer algo para sostenerse en la existencia, cuenta con la necesidad de anticiparse a la circunstancia para saber a qué atenerse frente a ella, de forma que adquiera esquemas de lo que son las cosas del mundo, es decir, convicciones. Como las convicciones son en su mayoría heredadas por otros, entonces se puede decir que el ser humano cuenta con lo hecho por ellos. El ser humano cuenta entonces con convicciones de un determinado tipo. ¿Cuáles son estas convicciones que tienen el poder de realidad que obliga al ser humano a contar con ellas, a estar frente a ellas en el modo ineludible de la presencia de la vida?

Ortega propone un ejemplo en su ensayo Ideas y creencias. ¿En qué cosas puede pensar de forma explícita un hombre que decide salir a la calle? Puede pensar en el motivo de su salida. Por ejemplo, comprar algo de comer. Puede pensar en que tiene hambre, en lo que quiere comer, en cuánto dinero necesita, etc. Puede pensar todo lo posiblemente implicado en la acción de salir a la calle, pero es casi seguro que a este hombre no se le ocurrirá jamás pensar que, una vez cruce el umbral de su puerta, la calle estará ahí. ¿El que no haya pensado en la calle significa que su existencia no tiene importancia en su acción? Ciertamente no. El hecho de que la calle esté es en buena parte lo más importante para que la acción pueda realizarse. La prueba de ello está en imaginar qué pasaría si, al abrir la puerta, hubiera un abismo en lugar de la calle. Se produciría una violenta sorpresa en el hombre, dice Ortega (1964). Esa sorpresa evidencia que la persona daba por sentada la existencia de la calle, aunque no pensara en ella y precisamente porque no pensaba en ella (Cf. V, p. 386). Este dar por sentado constituye un fenómeno que Ortega llama "creencia". 
Las creencias son convicciones sobre la circunstancia con las cuales el ser humano se encuentra ya en su vida, hacen parte de su presencia. Para Ortega (1964), el ser humano no piensa las creencias, sino que simplemente cuenta con ellas (Cf. V, p. 386). Como las convicciones que adoptan la forma de creencias entran en el ámbito de la presencia de la vida, Ortega (1964) afirma que estas son aquello que confundimos con la realidad misma (Cf. V, p. 385). En otras palabras, lo que el ser humano asume como realidad es un conjunto de interpretaciones, es decir, formas de saber a qué atenerse frente a lo que le rodea. Como las creencias son tomadas como la realidad misma, entonces es aquello sobre lo cual no hay problemas. Son el componente de facilidades de la circunstancia.

Esta definición básica de las creencias se distingue de lo que Ortega llama "ideas". Estas son otro tipo de convicciones cuya característica principal es el poder ser pensadas de manera explícita, de lo cual se deriva la posibilidad de poder ser discutidas, analizadas, defendidas o refutadas. Otro rasgo de las ideas es el hecho de que el individuo que las piensa ya existe antes de pensar o adoptar la idea. Las ideas son el producto del esfuerzo intelectual por resolver las dificultades que impone la circunstancia. Estas dificultades se dan porque las creencias no bastan para comprender la circunstancia en su totalidad. La circunstancia también pone al ser humano ante la duda, una realidad frente a la cual el ser humano no sabe a qué atenerse. Ante la duda, dice Ortega (1964), el hombre piensa y crea ideas para saber qué hacer con la circunstancia (Cf. V, p. 394).

Por lo demás, no todas las creencias son "puras creencias" ni las ideas son "puras ideas". En efecto, en Historia como sistema, Ortega afirma que hay creencias cuya fe es firme y otras cuya fe es débil y pueden empezar a ser cuestionadas al igual que las ideas. Así como hay creencias tan fuertes como la existencia de la calle al abrir la puerta, hay otras que no tienen mayor efecto a la hora de comprender la circunstancia, aunque tengan cierto margen de acción en la vida humana. Un ejemplo de esta creencia cuestionada, dice Ortega (1964), es la fe en la racionalidad moderna cuya efectividad es puesta en tela de juicio a lo largo del siglo XX (Cf. VI, p. 20ss.). De igual manera, hay ideas cuya influencia es más fuerte por diversas causas: su lógica, su aceptación por una mayoría, etc. Existe, por ejemplo, la creencia generalizada de que el exceso de ciertas comidas es malo para la salud.

En este sentido, tanto creencias como ideas pueden tener distintos niveles de problematicidad o suposición. Según la interpretación de Lasaga (1994), pueden haber "creencias tradicionales, creencias de autoridad, opiniones recibidas, experiencias de la vida, ideas-conocimiento, ideas-ocurrencias, ideas auténticas" (p. 224). Estos distintos niveles señalan que la diferencia fundamental entre 
una creencia y una idea no radica en su contenido, sino en el papel que juegan en el contexto de una vida humana. Ahora bien, la pregunta que surge a partir de esta distinción es la siguiente: ¿Es posible que una interpretación pase de creencia a idea o viceversa?

El ser humano está obligado a interpretar la circunstancia para saber qué hacer en ella. Si el producto de este esfuerzo logra dar las facilidades para resolver un problema de la circunstancia, es probable que tal interpretación se convierta en creencia ya que esta se hace de la realidad misma. De esto se sigue que las creencias de un ser humano comenzaron por ser ideas en algún momento de la historia, las cuales se consolidaron y pasaron a ser tomadas como la realidad misma. Ortega (1964) lo explica de la siguiente manera:

Conste, pues, que lo que solemos llamar 'mundo real' o 'exterior' no es la nuda, auténtica y primaria realidad con que el hombre se encuentra, sino que es ya una interpretación dada por él a esa realidad, por tanto, una idea. Esta idea se ha consolidado en creencia. Creer en una idea significa creer que es la realidad, por tanto, dejar de verla como mera idea. (V, p. 402)

De igual manera, hay creencias que dejan de responder a los problemas que la circunstancia plantea. Cuando esto sucede, si bien pueden seguir teniendo margen de acción y vigencia social por un tiempo, estas creencias dejan de ser la realidad misma. Por ejemplo, la crisis de la fe en la razón en el siglo XX que Ortega (1964) describe solo fue posible porque esa creencia actuó como tal en la vida de los hombres de una época. Estos hombres la crearon en medio de la crisis de la fe en Dios y se alcanzaron diferentes niveles con el paso del tiempo (Cf. VI, p. 42).

Así pues, hay un proceso permanente de consolidación y debilitamiento de interpretaciones sobre la circunstancia. En este proceso hay un paso por distintos niveles, los cuales dependen del factor facilidad-dificultad. En efecto, de la capacidad de resolver los problemas de la circunstancia depende que una idea devenga creencia absoluta o creencia debilitada, sea idea vigente, permanezca como mera ocurrencia o simplemente se desvanezca.

Los distintos niveles de una interpretación pueden cargar con cierta ambigüedad que no permiten distinguir claramente entre una idea o una creencia. Por ejemplo, como explica la interpretación de Lasaga (1994): "las ideas de opinión pública —ideas reinantes en amplios sectores de la sociedad- son discutibles y patentes, esto es, son ocurrencias, pero tienen vigencia, característica de las creencias" (p. 225). Aquí se manifiesta una característica fundamental de las creencias que permitirá entender esta aparente ambigüedad y que conducirá al asunto principal de este trabajo, a saber, entender la fenomenología orteguiana del mundo social. En efecto, ¿qué significa que algo sea vigente? 


\section{Vigencias y usos. El mundo social}

Dice Ortega (1964): "La creencia es certidumbre en que nos encontramos sin saber cómo ni por dónde hemos entrado en ella. Toda fe es recibida" (V, p. 407). Esta aseveración de Ortega es clave para entender la "vigencia colectiva" de las creencias. Al llegar a la vida, el ser humano ha comenzado a recibir distintas interpretaciones. Si las creencias son recibidas es porque cada uno asiste desde el principio a una realidad con la cual debe contar: recibe creencias por parte de otros seres humanos. Todo el que llega a la vida se encuentra con determinados otros. En el contexto de su análisis de la realidad social en El hombre y la gente, el encuentro con otros es una realidad fundamental al punto de que, para Ortega, este encuentro se da incluso antes de descubrir cada uno su propio yo. Para el español, el ser humano lleva en sí una fundamental apertura al otro, aunque esta se manifieste en la hostilidad o en la búsqueda de soledad, pues dicha apertura es la condición de toda relación social posible. Hay entonces una creencia fundamental en el ser humano: hay otros. Ortega (1964) describe esto como el "mutuo contar con" o la "reciprocidad" (Cf. VII, pp. 148-150).

Ahora bien, para Ortega (1964), la adquisición de creencias es posible bajo la condición de este "mutuo contar con". Si bien la vida de cada uno es radicalmente distinta de la vida del otro, un elemento común puede coincidir entre ambas. Estos elementos comunes pueden darse a su vez en muchos individuos. En consecuencia, el ser humano adquiere la noción creencial de un mundo común y objetivo aparte de la propia vida, a partir del cual todos los seres humanos pueden entenderse (Cf. VII, p. 151). El mundo es concebido entonces a partir de instancias comunes fundamentales para que el quehacer en la circunstancia esté mediado en primer lugar por los otros. Sobre esto último dice Ortega (1964):

Como ese mundo humano ocupa el primer término en la perspectiva de $\mathrm{mi}$ mundo, veo todo el resto de éste y mi vida y a mí mismo, al través de los Otros, de Ellos. Y como Ellos en torno mío no cesan de actuar, manipulando las cosas y sobre todo hablando, esto es, operando sobre ellas, yo proyecto sobre la realidad radical de mi vida cuanto les veo hacer y les oigo decir -con lo cual aquella mi realidad radical tan mía y solo mía queda recubierta a mis propios ojos con una costra formada por lo recibido de los otros hombres, por sus tejemanejes y decires y me habitúo a vivir normalmente de un mundo presunto o verosímil creado por ellos, que suelo dar, sin más, por auténtico y considero como la realidad misma. (VII, p. 177-178)

Los otros tienen entonces un papel fundamental en la conformación del propio mundo a partir del cual cada uno realiza el quehacer de su vida en la circunstancia. Los otros regulan las posibilidades del quehacer y las interpretaciones acerca de lo que rodea a un ser humano. Pero estos otros no son determinados otros, sino que conforman un fenómeno que Ortega considera fundamental para 
entender en qué consiste la sociedad. Ortega (1964) pone el ejemplo del día de disfraces. ¿Por qué las personas se disfrazan un día específico y no otro? Porque es la costumbre, es lo usual, es lo que se hace (OC, VII, p. 198). Si una persona se disfraza en el día no acostumbrado, su acción no será desaprobada por la iniciativa de alguien específico, sino por el colectivo en general, es decir por la gente. Las miradas de desaprobación, los murmullos o las risas son la muestra de la acción efectuada por un colectivo informe del cual nadie es responsable. La gente ordena a los individuos para que adopten ciertos comportamientos, piensen ciertas cosas, digan unas cosas y dejen de decir otras. Si bien una persona puede decidir apartarse de algunos de estos mandatos, termina adoptando otros sin darse cuenta, pues la creencia en el mundo común conlleva a que los asuntos sean comprendidos en su mayoría desde los lentes de la colectividad. El ser humano, gracias a este colectivo que le imprime formas de estar en el mundo, lleva la sociedad en su interior (Cf. Ferreiro, 2005, p. 97).

La gente regula las posibilidades del individuo a través de los "usos". Los usos funcionan entonces como instancias reguladoras. Pero Ortega (1964) no se queda corto y afirma que tales usos son la primera y más fuerte realidad con la que uno se encuentra. (Cf. VII, p. 211). La razón de esto es que cada uno está primariamente inserto en una sociedad que es, como afirma Ferreiro (2005) en su interpretación, un conjunto de seres humanos sometidos a valoraciones vigentes manifestadas en un sistema de usos (Cf. p. 109). Lo que se había explicado antes en términos más abstractos como el "contar con" tiene ahora un contenido concreto que depende de los usos de una sociedad.

Ahora bien, el uso es vigente porque se impone con o sin el beneplácito de los individuos. Al igual que la creencia, Ortega (1964) dice que el uso es algo con lo que todos tienen que contar (VI, p. 19). La forma como el uso guía la acción humana poco tiene que ver con la frecuencia de un acto. Tal como advierte Ortega, algo no es vigente porque se haga de forma continua. ¿Cuándo se dice entonces que algo es un uso? Cuando adquiere el carácter de norma social con posible coacción a su incumplimiento. Un uso es tal cuando funciona como regulador de la convivencia de la sociedad (Cf. Ferreiro, 2005, p. 112). Los reguladores de la convivencia no son solo las leyes, también pueden ser los actos o palabras más simples. No es gratuito que Ortega tome el saludo como un ejemplo central de su teoría del uso.

Alguien decide ir a una fiesta, comienza a comentar Ortega (1964). Esa acción proviene de su voluntad, tiene su origen en él y tiene sentido para él. Pero al llegar a la fiesta se encuentra con que toma la mano de cada una de las personas presentes, la mueve hacia arriba y hacia abajo y luego la suelta, mientras dice palabras como "hola, qué tal", "mucho gusto", etc. Esta acción no hace parte de 
la fiesta, no fue algo acordado entre los presentes. Nadie sabe en el fondo por qué hay que realizar una acción como esa al iniciar contacto con otra persona. Nadie sabe por qué se hace, pero es algo que se hace. Saludar es una acción particular que nadie entiende. ¿Por qué precisamente dar la mano y no inclinarse bajando la cabeza como en Japón? El saludo es en últimas una acción humana que no ha sido inventada por quien la realiza, sino que es ejecutada por repetición y que en el fondo no tiene sentido (Cf. VII, p. 207-210). Si una persona no realiza esta acción sin sentido, puede ser tomado como maleducado o antipático. Esta es la indicación de su carácter normativo y coactivo en tanto uso.

Las consecuencias negativas de contrariar un uso pueden ser más o menos graves dependiendo de este mismo. Ortega clasifica los usos en dos grupos. En el primer grupo están los "usos débiles y difusos", compuestos por las costumbres del trato social corriente: vestir, comer, decir, pensar. El segundo contiene los "usos fuertes y rígidos", compuestos por todo lo referente al derecho y al Estado. No vestir como viste la gente puede tener como coacción el murmullo y la risa, no comer lo que la gente come puede tener como coacción la dificultad para conseguir los alimentos que se quieren. Estas coacciones son de una fuerza menor a aquellas provenientes de los usos fuertes: cometer una infracción de tránsito acarreará una multa; incumplir una ley lleva a la cárcel. Estas consecuencias son más notorias y graves. Todos estos ejemplos dados por Ortega apuntan no obstante a lo mismo: el carácter coercitivo de los usos de una sociedad, es decir, la imposibilidad de elegir otro comportamiento so pena de grandes dificultades. Es así como concluye Ortega (1964):

Este es el momento de corregir en poquísimas palabras la idea errónea que de la coacción social o colectiva se tiene. Pues se supone que esta ha de consistir en actos especiales, positivos o negativos, que los demás ejerzan sobre nosotros. No hay tal. Esa es solo una forma de coacción de la cual hemos visto ya dos especies distintas: el enfado de los demás si no les saludamos, que es mera retirada de su amistad, de su estima y tal vez de su trato, y la intervención enérgica de la policía si alguien roba un reloj o falsifica un testamento. Pero me parece perfectamente natural llamar 'coacción sobre mi comportamiento' toda consecuencia penosa, sea del orden que sea, producida por el hecho de no hacer yo lo que se hace en mi contorno social. [...] Digamos, pues, que hay coacción siempre que no podamos elegir impunemente un comportamiento distinto de lo que en la colectividad se hace. (VII, p. 236)

Tal como apunta Ferreiro (2005), "todo uso encierra creencia" (p. 120). El uso lleva en sí la creencia porque es algo que está ahí antes de cada persona. Al mismo tiempo, tal como lo apunta Ortega (1964), su conjunto es el establecimiento colectivo de un estado de fe (Cf. VI, p. 19). No obstante, la creencia propia de los usos se manifiesta mejor en su carácter de sedimentación histórica. Los usos, según Ortega (1964), fueron acciones humanas de las cuales se sabía su sentido en algún momento de la historia, mas con el paso del tiempo se mecanizaron, 
se automatizaron y su realización empezó a estar motivada simplemente por una obligatoriedad social cuyo origen y responsabilidad nadie conocía (Cf. VII, p. 216).

Lo mismo, según Ortega, sucede con las palabras. ¿Por qué a la acción de mandar se le dice precisamente "mandar"? Al igual que con el saludo, Ortega reconstruye las formas previas de la palabra "mandar" para dar con la forma inteligible y con sentido que dio origen a la palabra: in manus esse y manus dare, que en latín significan tener dominio sobre otro o ejercer fuerza sobre él. Para descubrir el sentido de una palabra, continúa Ortega (1964), se busca su etimología; y sobre esto afirma: "[L]as palabras no tienen etimología porque sean palabras, sino porque son usos" (VII, p. 220). Los usos y las palabras son formas sedimentadas de acciones concretas que tuvieron lugar en un momento lejano de la historia, al igual que las creencias son producto de la sedimentación histórica de determinadas ideas.

La mayor parte de los ámbitos de la vida humana está imbuida por usos y creencias; lo que mejor ejemplifica esta afirmación es el lenguaje. A este tema dedica Ortega los últimos dos capítulos de El hombre y la gente. El ser humano tiene una intención de decir, lo cual tiene sentido para él. Ahora bien, ¿sabe el individuo por qué debe decir con ciertas palabras en vez de otras? ¿Por qué un sentimiento como el amor, pregunta Ortega (1964), se dice "amor" y no con cualquier otro sonido? La cuestión se entiende: la palabra como tal ya estaba ahí desde mucho antes que el individuo que la pronuncia con una intención inteligible (Cf. VII, p. 234). Las palabras que encarnan una expresión son provistas por la sociedad. El habla se aprende en el decir de la gente. De esta manera, la lengua es un uso y como tal es algo con lo que el ser humano debe contar. De igual forma, la lengua ejerce coacción sobre el individuo. Tal vez un Estado no sancione el no uso de una lengua, tal vez los demás no tomen a la persona por maleducada. La coacción, menos agresiva, es mucho más efectiva: el ser humano no se hace entender, no logra dar a conocer lo que quiere decir.

La lengua en tanto uso es igualmente el producto sedimentado de una creación que en algún momento tuvo sentido. Esta creación tiene su base en una necesidad del ser humano previa a la lengua: el decir. Antes que la palabra, está la necesidad humana de dar cuenta de una realidad. La palabra es en esta medida inseparable de quién la dice, a quién la dice y en qué situación. Pero no solo es necesaria la palabra: la voz, el gesto, los silencios, la situación, también hacen parte del decir. La lengua como uso, según Ortega (1964), ya provee en la gran mayoría de los casos las formas de decir algo. Pero si hay una realidad para la cual la lengua vigente no tiene las palabras adecuadas, el individuo que necesita decir algo puede crear nuevas expresiones, las cuales pueden llegar a 
convertirse en usos si logran solucionar la dificultad a la hora de decir (Cf. VII, p. 254). La lengua se mueve entonces en ese proceso de imposición, creación y sedimentación.

Ahora bien, aunque un individuo invente formas nuevas de expresión y estas se conviertan en uso - lo cual para Ortega tiene pocas posibilidades de darse y, si se logra, toma mucho tiempo-, aquél está siempre imbuido por el decir de la gente y la lengua como uso. La sociedad inyecta el lenguaje en el individuo; mas lo puesto no son solo palabras. Si con las palabras se dice algo, no es menos cierto que, al imponerse el uso de una lengua en el individuo, también se imponen las posibilidades de decir que las palabras pueden tener. En suma, no solo se usan las palabras, sino también las ideas-en sentido laxo y no en el sentido filosófico de Ortega - que con ellas pueden venir. Si con las palabras vienen inyectadas ideas, es decir, convicciones sobre la circunstancia, esto significa que el lenguaje como uso nos pone realidad, nos pone creencias. La consecuencia es que si la vida humana es un quehacer con la circunstancia que consiste en primer lugar en interpretarla, resulta que gran parte de la labor interpretativa tiene su base en lo que ya la sociedad le ha dado al ser humano. La aseveración de Ortega (1964) es muy clara en este sentido:

Pues bien, la mayor parte de las ideas con que y desde las que vivimos no las hemos pensado nunca nosotros por cuenta propia, ni siquiera las hemos repensado. Las empleamos mecánicamente a cuenta de la colectividad en que vivimos y de la cual han caído sobre nosotros, nos han penetrado a presión, como en el automóvil el lubricante. [...] De donde resulta que la inmensa mayoría de nuestras ideas, a pesar de ser ideas y actuar en nosotros como convicciones, no son nada racional, sino usos como la lengua o el saludo; en definitiva, no menos mecánicos, ininteligibles e impuestos a nosotros que ellos. (VII, pp. 262-263)

Así pues, esas ideas que nos vienen inyectadas con las palabras son en el fondo creencias, pues son lo que viene con el uso de la lengua. Lo que pensamos no es producto de nuestra propia cuenta, sino el resultado mecánico de la vigencia de la colectividad, es decir, lo usual para pensar. Lo que antes ha sido llamado "mundo común" adquiere un contenido preciso: los usos, y en particular la lengua como uso que pone al ser humano en consonancia con determinadas interpretaciones con las cuales tiene que contar. El mundo común es entonces un mundo social cuyo contorno está lleno de opiniones.

En el último capítulo de El hombre y la gente, Ortega explica que la sociedad maneja dos clases de opiniones: 1) las opiniones particulares, de las cuales el opinante sabe que debe dar razones; no son otra cosa que las ideas. 2) Las opiniones reinantes, aquellas que son admitidas por ese sujeto imperceptible llamado popularmente "todo el mundo"; son aquellas que no necesitan en principio ser justificadas, sino que ejercen sobre los miembros de la colectividad 
su coacción de uso y sirven como instancia. Esas opiniones reinantes, advierte Ortega (1964), no son determinadas opiniones explícitas que sostiene la mayoría. Lo que esta defiende es la opinión particular de un grupo. Pero la opinión reinante no necesita defensores, sino que predomina sobre los decires y quehaceres de todos los individuos (Cf. VII, p. 265). Estas opiniones dominantes son llamadas por Ortega "tópicos". Toda sociedad está llena de tópicos y existe con base en ellos. Esta imposición mecánica de los tópicos en los individuos hace a su vez que éstos vigilen el cumplimiento permanente de estos. La vigilancia es la muestra fehaciente de que la sociedad es un poder impositivo frente a las posibilidades del individuo. La sociedad, para Ortega (1964), es en esencia "poder público". Así lo explica:

La sociedad, conjunto de los usos, de un lado se nos impone; de otro, la sentimos como instancia a que recurrir y en que ampararnos. Lo uno y lo otro, ser imposición y ser recurso, implican que la sociedad es, por esencia, poder, un poder incontrastable frente al individuo. La opinión pública, la opinión reinante, tiene tras de sí ese poder y lo hace funcionar en las diversas formas que corresponden a las diversas dimensiones de la existencia colectiva. Ese poder de la colectividad es el 'poder público'. (VII, p. 266-267)

El poder público no requiere necesariamente de instituciones; al ser la manera como una sociedad mantiene su visión de lo que es la realidad misma, este poder solo precisa mantener la apelación y la imposición de sus supuestos, para lo cual requiere la labor inconsciente y permanente de la vigilancia mutua de todos los individuos. De ahí la conclusión de Ortega (1964) según la cual "[l] a colectividad vigila — sin proponérselo_ cada minuto de la vida individual" (VII, p. 268).

\section{Conclusiones}

La definición que da Ortega de "mundo" en En torno a Galileo como conjunto de convicciones que un ser humano posee a partir del entorno espacio-temporal en que se encuentra nos pone ante la vista el carácter ya interpretado de la realidad con que el ser humano se encuentra. Las interpretaciones con las que se encuentra son convicciones. Unas son respuestas ya dadas a la circunstancia, las cuales se confunden con la realidad misma, es decir, son creencias y otras son producto del esfuerzo intelectual del individuo por responder a los problemas circunstanciales que no encuentran respuesta en el repertorio de respuestas ya establecido, es decir, son ideas. Las creencias son producto de la sedimentación histórica de ciertas ideas que lograron responder a los problemas de la circunstancia. En el establecimiento de estas convicciones de los individuos juega un papel fundamental el encuentro con los otros. La apertura esencial del ser humano hacia los otros posibilita la creencia en un mundo común y objetivo. 
Ese mundo se teje con las creencias, aquello que en una colectividad es considerado como la realidad misma. De ahí que las creencias sean necesariamente colectivas o sociales. Todo cuanto el individuo considere por sí mismo cuenta en principio con el repertorio interpretativo de una colectividad. ¿Qué es lo que impone la colectividad? Los usos, todo aquello que un ser humano hace, dice o piensa simplemente porque los demás hacen lo mismo. Resulta que estos constituyen la enorme mayoría de todo lo que constituye la vida humana. El ejemplo fundamental del uso es el lenguaje, pues a través de él se insuflan en cada uno los pensamientos vigentes por medio de las palabras, las cuales son también sedimentaciones históricas de expresiones que en algún momento tuvieron un sentido concreto. Los usos, como explica Ortega (1964), son una realidad con la que se debe contar so pena de la coacción de la colectividad, la cual no se manifiesta necesariamente en sanciones, sino más bien en dificultades para la acción. Al imponer un repertorio de acciones, dichos y convicciones, las creencias responden a gran parte de la realidad, facilitan su interpretación y permiten que el ser humano se concentre en aquello para lo que no hay una respuesta de tipo creencial. Esto quiere decir que, gracias a los usos y las creencias, el ser humano puede concentrar dificultad en lo que representa, para lo cual no hay respuesta inmediata, sino que necesita ideas (Cf. VII, p. 78).

El contenido de este trabajo ha seguido un camino desde una postulación abstracta del problema de la correlación ser humano-mundo hasta la explicación de su manifestación concreta en términos socio-históricos. La vida como coexistencia entre el yo y la circunstancia tiene un carácter eminentemente ejecutivo, es decir, de acción o quehacer en medio de la presencia permanente que es la vida misma. Se ha visto que una parte fundamental de tal presencia permanente es todo el contenido interpretativo que la sociedad ha inoculado en el individuo. Este contenido interpretativo toma las formas más variopintas entre dichos y acciones. Pero todo ello confluye en lo mismo: es aquello con lo que al vivir se cuenta, como dice Ortega. Si como explica Milagro (2015), uno no "tiene" tanto la creencia como más bien la "es", entonces el ser humano es todo un repertorio interpretativo de realidad que lo pone en la base de una serie de respuestas ya dadas (creencias, usos, vigencias) y dificultades que pueden surgir a partir de ellas (de donde surgen las ideas). La creencia, como explica Milagro (2015), es "el darse evidencial de la coexistencia ejecutiva en que consiste el vivir." (p. 141). Se ve que este darse no tiene nada de etéreo, sino que está lleno de contenido.

Una última pregunta que resulta de estas consideraciones es la siguiente: ¿Hay alguna posibilidad de pensar una realidad libre de interpretaciones, más exactamente libre de creencias? Ortega (1964) da su respuesta en Ideas y creencias. Si las creencias son producto de la sedimentación histórica de ideas y si además son aquello que el ser humano confunde con la realidad misma, 
resulta que "la realidad en que creemos vivir, con que contamos y a que referimos últimamente todas nuestras esperanzas y temores, es obra y faena de otros hombres y no la auténtica y primaria realidad" (V, p. 399).

La respuesta a la pregunta sería entonces que no se puede tener una figura concreta de la realidad auténtica. Como las ideas son producto del esfuerzo por responder a una dificultad generada por la falta de una respuesta creencial o, en otras palabras, son la respuesta a un enigma, y las creencias son la sedimentación de ideas, resulta que una realidad completamente libre de interpretaciones sería un enigma absoluto. Toda vida humana tiene su componente esencialmente enigmático y con base en unas creencias, el hombre se aboca a resolver estos enigmas. Sin base creencial, la realidad sería puro problema. El ser humano crea formas de interpretar la circunstancia para responder a los enigmas que esta propone. En la medida en que con estas interpretaciones se facilita el quehacer de la vida, se toman como la realidad misma.

Se puede ver entonces cómo en Ortega existe la advertencia sobre una esencial oscuridad en el intento de ir más allá de aquello que condiciona al ser humano. Si bien el hombre tiene experiencia de lo enigmático gracias a que las creencias no logran solucionar todo lo que puede presentarse en la circunstancia, es cierto que la noción de un "enigma absoluto" es algo que no se podría dimensionar en su totalidad. Las creencias ya han puesto al ser humano en un marco que no solo incluye nociones de realidad sino también formas de acción con las cuales se conduce la vida. Si el hombre se despoja de todo ello, le queda una nada inconcebible y absolutamente problemática sobre la cual no podría haber quehacer alguno y, por tanto, no se podría vivir. Mientras exista la posibilidad de tener una vida humana, es decir, de hacer algo con la circunstancia, siempre se tendrá implícitamente presente un repertorio de interpretaciones que se da por sentado. Esta es la absoluta realidad con la que indefectiblemente se debe contar.

\section{Agradecimientos}

Este artículo es producto del trabajo de investigación La vida humana y los condicionantes de la comprensión. Un análisis comparativo entre Martin Heidegger y José Ortega y Gasset desde los tópicos 'condición de arrojado' y 'creencia', presentado para la maestría en Filosofía de la Universidad de Antioquia. De igual manera, está enmarcado en el proyecto de investigación Tiempo, historicidad y lenguaje en la filosofía hermenéutica y la fenomenología (Universidad de Antioquia - CODI SIIU 2014-980 - enero de 2015 - mayo 2018) del profesor Andrés Francisco Contreras, en el cual el autor de este artículo estuvo vinculado como estudiante en formación. 


\section{Referencias}

Ferreiro, I. (2005). La teoría social de Ortega y Gasset: los usos. Madrid: Biblioteca Nueva. Fundación José Ortega y Gasset.

Husserl, E. (1990). El artículo de la Encyclopaedia Britannica. México D.F.: UNAM.

Lasaga, J. (1994). Las creencias en la vida humana. Una aproximación a la distinción orteguiana entre ideas y creencias. Éndoxa. Series filosóficas, 4(1), 205-231.

Milagro, A. (2015). Las creencias en el proyecto metafísico de Ortega y Gasset. Madrid: UNED.

Ortega y Gasset, J. (1964). Obras completas. Tomo V. Madrid: Revista de Occidente.

Ortega y Gasset, J. (1964). Obras completas. Tomo VI. Madrid: Revista de Occidente.

Ortega y Gasset, J. (1964). Obras completas. Tomo VII. Madrid: Revista de Occidente.

Ortega y Gasset, J. (1965). Obras completas. Tomo VIII. Madrid: Revista de Occidente.

Ortega y Gasset, J. (1966). Obras completas. Tomo I. Madrid: Revista de Occidente.

Ortega y Gasset, J. (2004-2010). Obras completas. Tomo IV. Madrid: Taurus.

Ortega y Gasset, J. (2004-2010). Obras completas. Tomo VIII. Madrid: Taurus.

Rodríguez, A. (1981). La innovación metafísica de Ortega. Madrid: Ministerio de Educación y Ciencia. 